\title{
Corpus-based Contrastive Analysis of “Root” Metaphor Translation in Dream of the Red Mansion
}

\author{
LIU Xiao \\ Nanjing University of Aeronautics and Astronautics, Nanjing, China
}

\begin{abstract}
Both the study of metaphor and translation has taken an empirical turn in the past decade, corpus-based method has provided a practical and objective way for investigating metaphor translation from a comparative and cognitive perspective. The purpose of this paper is to reveal the cognitive differences in the perception of "root" between English and Chinese through a contrastive analysis of the two English translations of a Chinese classic novel—Dream of the Red Mansion, the two translations are completed by a native Chinese speaker and a native English speaker respectively. The study is divided into two parts, the first part is devoted to a contrastive analysis of typical examples selected from the data acquired from the online English-Chinese parallel corpus with the online corpus analysis tool Wmatrix, two deductions have been drawn through the analysis concerning the cognition difference in root perception: (1) the integral perception of root and a plant in Chinese VS the binary cognition in English; (2) the concreteness of "root" metaphor in Chinese VS the abstractness in "root" metaphor application in English. Then the two deductions are further demonstrated through corpus-assisted study of "root" metaphor in large online corpuses. The differences in root metaphor usage as well as the cognitive reasons behind the differences have been investigated with emphasis not only on the dominant conceptual root metaphors, but also the semantic preference of the collocated words of the metaphors.
\end{abstract}

Keywords: "root” metaphor, Dream of the Red Mansion, corpus-based comparative analysis, cognitive structure

\section{Introduction}

Metaphoricity is used to measure the degree of metaphor's novelty. Poetic metaphors are normally more evocative, which are deemed as possessing a higher degree of metaphoricity; while metaphors frequently adopted in daily converstaion tend to raise little metalinguistic thinking. Both speaker and listener interpret those metaphors subconsciously, in other words, there is no tension between the symbol adopted and its cognitive representation. Hawkins (2001) has pointed out that social and cultural cognition is rooted in group habit and mental model, which forms in the long-term social interaction; and the influences of these solidified communal cognitive resource are to a large degree subconscious. So it's reasonable to hypothesize that metaphors with lower degree of metaphoricity can fit in the cognitive structure in our brain easily , and thereby can be used as a window for us to study how human minds work.

This paper conducts a contrastive cognitive analysis of a specific metaphor-metaphors based on the

LIU Xiao, Ph.D., lecturer, College of Foreign Languages, Nanjing University of Aeronautics and Astronautics, Nanjing, China. 
"root" image, which can be included in Plant metaphor. Conversations between the characters in one of Chinese literary classic_-Dream of the Red Mansion will be used as materials for the study. More accurately, a comparison will be carried out between the root metaphors in the two English translation versions of the novel and the original. The two main research questions are: first, the difference between root metaphor translations and between the translation and original; second, the cognitive and culture differences in English and Chinese that lie behind the differences.

The reason that two translation versions of the novel are used for analysis is that we believe translation itself is a cognitive activity, a translator's mission is to depict the reality and thoughts of the authors based on his or her own interaction with the world (Wang, 2012). It's commonly acknowledged that metaphor translation is rather difficult, especially non-literary metaphors, that's because those so-called "dead" metaphors, metaphors with lower degree of metaphoricity, evolve on the specific cultural background and certain cognitive structure, it's the variance between them that upgrade the translation challenge.

So far, we have demonstrated the close connection between daily-used subconscious metaphors and our deep-lying cognitive structure, and that different translations of the same metaphor can reflect the variance between cognition and cultural pre-assumption. Besides, Frank (2008) mentioned that the cognitive pattern involved in discourse is traceable due to the restraints of culture. Xu (2014) also emphasized that the usage of metaphor mirrors the value judgement of the author. Thereby, the feasibility of the research design of this paper has already been proven.

The research consists of the following steps: firstly, based on the previous theories and with the assistance of the online corpus Wmatrix, "root" metaphors in The Dream of Red Mansion and the correspondent English translation are analyzed so as to reveal the cognitive difference between English and Chinese; secondly, key word search results in large online corpuses of English and Chinese are used to prove the cognitive differences with data support. The original material for metaphor analysis is selected from the English-Chinese parallel corpus of Dream of the Red Mansion formed by the Humanities and Science Institute of Shaoxing. The large online corpus used for the verification of the hypothesis includes the Modern Chinese Corpus of State Language Commision, and COCA. The first step mainly focuses on the difference of the number and main conceptual metaphor of "root" metaphors in the two English translations and the cognitive reasons behind the difference. The second step adopts quantitative method to provide corpus support for the conclusions made through the sentence analysis, then further contrastive analysis was carried out about the semantic preference and the pragmatic value of root metaphor.

\section{Literature Review}

The study of metaphors in Dream of the Red Mansion accentuates poetic and literary metaphor, while pays little attention to the metaphors with lower degree of metaphoricity in the dialogue of characters. At the same time, the research purposes of most relevant studies of metaphor translation are the strategy of tranlation or the style of translators, cognitive pragmatic approach is rarely applied to metaphor translation. As a matter of fact, metaphor translation is not only the equivalent research at the language level, it's more about the blending and exchanges between different cognitve structure and cultural background. The application of core principles of cognitive linguistics in metaphor translation is closely associated with the exploration of cognitive mechanism 
(Wang, 2014). The study of metaphor translation opens a way to the the revelation of cultural and cognitive differences. One critical issue of cognitive metaphor study is that most research rely solely on the author's reflection, corpus linguistics can complement this research model by providing objective data and statistics. The combination of cognitive linguistics and corpus linguistics has become an irreversable trend. As one of the key topics of cognitive linguistics, metaphor study should make full use of online corpus to provide statistical support for the hypothesis or preliminary conclusion.

\section{The Number and Proportion of "Root" Metaphor in the Original Text and the Translation}

Firstly, by searching the key character «根» (root) in the online English-Chinese parallel corpus of The Dream of Red Mansion, we found that «根» appeared 101 times in the corpus, among which 49 are quantifiers, and of the remaining 52 sentences, 34 metaphors were identified, which means the metaphor proportion of all sentences involving «根» is as high as $65 \%$.

Then we compared the English version translated by Hawkes with the BNC (sample written), and in the "Plant” thematic domain we found that "root", "roots" and "rooted" are used 25 times, among which only 6 "root" metaphor, the metaphoric proportion is $24 \%$. The same search method is applied to Yang's transltion, in which we found 28 places involving "root", and 13 "root" metaphors, metaphoric proportion is $46 \%$. The statistics are listed in the following table.

Table 1

Root Metaphor Proportion in Chinese and English Translations

\begin{tabular}{llll}
\hline Text & Root & Root metaphor & Root metaphor (\%) \\
\hline Chinese & 52 & 43 & $65 \%$ \\
Yang's text & 28 & 13 & $46 \%$ \\
Hawkes's text & 25 & 6 & $24 \%$ \\
\hline
\end{tabular}

The following preliminary results can be drawn from Table 1: (1) The propotion of root metaphor in the original Chinese text is very high (65\%), which means compared with its literal usage, "root" is more frequently used metaphorically, such as "life root”, “disease root”, “disaster root”, “wall root”, "togue root”, "window root"etc.; (2) The proportion of root metaphor in the two English versions is much lower than the orignal text, which indicates that a large portion of "root" metaphor in the original Chinese text has not been reserved, paraphrasing replaces literal translation; (3) The proportion of "root" metaphor in Yang's translation is obviously higher than Hawkes's version, the differences arise from the translators' translation purpose, strategy, their perspective in comprehending the original text, as well as the cognitive and cultural background of the translators.

The hypothesis of this paper is that the main reason leading to various interpretations of the translator of "root" metaphor lies in the cognitive difference betweeen English and Chinese native speakers, which is closely under the influence of cultural pattern and ideology. Although there have been plenty studies about the translation of Dream of the Red Mansion, most research attrribute the reason of different translation to the intended choice of the translators to meet certain purpose, for example, Yang tries to spread traditional Chinese culture, that explains why he reserves more literal forms of "root" metaphor than Hawkes, who puts more emphasisi on the simplification of the understanding process of English readers. We admit that the choice and 
intention of translators do play an important role in the different metaphor translations, but subconcsiouly, the deep-lying cognitive model and cultural preassumption play a bigger role in determining the translator's perspertive, resulting in difference understandings of the same metphor, which leads to various translations. The next part of the paper will list several examples extracted from both the Chinese original and the two English transltions.

\section{The Cognition of Root in Chinese and English}

By combing through the Chinese materials, we classified the plant meatphors in The Dream of Red Mansions into five categories: PLANT AND FAMILY, PLANT AND SOCIAL RELATIONSHIP, PLANT AND DISEASE, PLANT AND LIFE, PLANT AND ARCHITECTURE. For Chinese, root is an inseparable part of any plant, so root metaphor can easily trigger the conceptual metaphor of the plant as a whole. The following example is based on the PLANT AND FAMILY conceptual metaphor.

a. 薛家根基不错, 且现今大富, 薛蚪生得又好, 且贾母又作保山。(第57回-412页)

(Xues have a good family root, and now they are very wealthy; Xue ke is very handsome, and Grandmother Jia will be the match-maker.)

b. Since the Xues came of fairly good stock and were now very wealthy, while Xue Ke was a handsome young man, and the go-between, moreover, was no less a person than the Lady Dowager. (Chapter 57, p. 579, Yang)

c. The Xue family were of respectable origins; they were immensely rich; Xue Ke was a good-looking boy; and Grandmother Jia was making herself responsible for the match. (Chapter 57, p. 614, Hawks)

In the bracket you can find the literal translation of the Chinese sentence, "a good family root” probably will confuse the English readers, that's why both Yang and Hawkes didn't chose the literal translation. The common cognitive background for Chinese is that FAMILIY IS PALNT/TREE, in which root is included in the whole tree image, so when the author wanted to express his positive evaluation of the family's origin and later development, "family root" is adopted; and it's enough to trigger the tree image among Chinese readers. However, the same image is not equally represented in English readers' minds, more specifically, the connection between root (undergound) and tree (the part of tree above the ground) is not very close in English reader's perception of a plant. What's above the ground is perceived as the image of the tree, while root, lying deep underground, is constantly omitted or at least weakened. That's why the metaphor is not copied into the translation, because the tree image is hard to be triggered, thus the FAMILY IS PLANT conceptual metaphor is not accessible either. Therefore, in Hawkes's translation, the "root" metaphor was paraphrased into "of respectable origins", compromising the metaphorical form to avoid misunderstanding; while in Yang's translation, "root" is mildly replaced by the word "stock", a part of the tree which connects the tree trunk and root. Yang's smart translation demonstrates both his comprehension of root as an inseperatable part of the tree, and his awareness of the English reader's possible confusion, so he chose "stock" as a go-between to shorten the cognitive difficulty and reserve some flavor of the "root" metaphor in the original text.

The binary cognitive perception of English is also reflected in the "root" metaphor translation of the following sentences:

d. 方剪草除根, 保住自己的名誉. (第六十九回, 第172页) 
(Cut the grasses and eliminate the root, so can you save your reputation.)

e. Only by such root-and-branch methods, she felt, could her fears be allayed and the threat to her reputation be removed. (Chapter 69, p. 1363, Hawks)

f. In this way the root of the trouble would be removed and her reputation assured. (Chapter 69, p. 1238, Yang)

Hawks's translation "root-and-branch methods" refers to the combination of rational thinking and practical method, it seems that the translation corresponds to the original expression in both form and content. However, the Chinese four-character phrase attaches much more importance to the uprooting part, and the cutting grass is simply a context. Therefore, it's actually Yang's translation "the root of the trouble would be removed" really revealed the author's intention, although it seems an incomplete translation since it does not mention grass at all.

The four-character structure of Chinese phrase exists for the sake of the phonetic rhyme rather than the expression of meaning. But it's difficult for westerners to recognize the focus of a phrase if they are not aware of the intention of four-character phrases. Yang as a Chinese native speaker, can easily sense the real intention of the author by using the phrase “剪草除根 (jian cao chu gen)”, which is equal to the sentence “if one wants to remove the grass, one has to uproot it", that's why he chose to only translate the "root" part and ignoring the "grass".

\section{The Concreteness of “根 (Root)” in Chinese and the Abstractness of "Root” in English}

Apart from the variance in the cognitive perception of the relation between root and tree trunk, the difference between English and Chinese cognitive structure also lies in the dergeee of abstractness. In the following sentence g, “病根 (disease root)” can be recognized as a specific metaphor of the conceptual metaphor "DISEASE IS A PIANT". By reading the two translations, it can be found that none of the translator has reserved the form of the metaphor-"get rid of the root of your illness", but rather chose the simpler expression "get rid of that/your illness".

g. 李纳道:“放风笔图的是这一乐, 所以又说放晦气，你更该多放些，把你这病根儿都带了去就好 了。”（第70回，504页）

h. "Kite-flying is just for fun, that's why we call it 'sending off bad luck," said Li Wan. "You should do this more often, and then you might get rid of that illness of yours. Wouldn't that be a good thing?” (Chapter 70, p. 741)

i. "But that's the main reason for flying kites," said Li Wan, "the pleasure of seeing them fly away. Not to mention the fact that it is supposed to get rid of your bad luck You of all people ought to let yours go, so as to get rid of your illness.” (Chapter 70, p. 746)

The reason that both translators gave up the metaphorical connection between illness and root is because the habitual English expression rarely uses root to depict a specific disease. By search "root of NONU" in BNC, $86 \%$ of the search results are abstract nouns like thought, thinking, innovation, perception, only 6 concrete nouns are located. And even these 6 concrete nouns are not associated with concrete items when the context is taken into account. The 6 concrete nouns-family, plant, man, land, knots, things—correspond to the root of 
family problems, root of plant mitochondria, root of man's capacity, root of land tenure, root of knots of hair, root of things respectively, the only concrete nouns "thing" and "knot" also appear in plural form.

The further search results of "root of a disease" in the searching engine are mostly "the root cause of diseases", collocation between "root" and a specific disease has not been found. Therefore, it can be seen that the reason why both Yang and Hawks chose to give up "root" metaphor is largely due to the semantic asymmetry of the meaning of "root". In Chinese, root metaphor is commonly used to indicate the reason of certain specific event, such as “病根 (disease root), 祸根 (accident root)”. On the contrary, root metaphor in English tends to go with abstract concepts or a large group of things, such as the root of thought, the root of violent, the root of world diseases", "the root of all chronic diseases".

The metaphor "root = the reason of a disease" has appeared 6 times in the original Chinese of Dream of the Red Mansion, while the correspondent metaphor translation in Yang's translation only appeared twice, and no correspondent metaphor found in Hawks's. Even in Yang's translation, the so-called two "root = reason of the illness" metaphors do not actually refer to the real disease per se. In sentence $j$, "if that's not the root of her illness", the illness here means Lin's love for Baoyu rather than the real illness; and in sentence $\mathrm{k}$, the "root-disease" metaphor is indirectly demonstrated through the verb "uproot”.

j. 林Y头若不是这个病呢, 我凭着花多少钱都使得。

If that's not the root of her illness, I'm willing to spend any sum to cure her. (Chapter 97, p. 1050)

k. 贾母等知他病未除根, 不许他胡思乱想......

Knowing that the cause of his illness was not yet uprooted, his grandmother... (Chapter 98, p. 1068)

The fact that "root" metaphor in English tends to coincide with abstract concepts is also reflected in the translation of "root of life" in the following sentence.

l. 贾母咳道：“这是宝玉的命根子，因丢了，所以他这么失魂丧魄的。（第95回，669页）

m. "This jade is the root of Baoyu's life," sighed—the old lady. "It's because he's lost it that he's out of his mind." (Chapter 95, p. 1036)

n. "The jade is Bao-yu's very life. Losing it is what has made him lose his wits.” (Chapter 95, p. 981)

"Root of life" metaphor is the instantiantion of the conceptual metaphor "LIFE IS A PLANT". Metaphor "LIFE IS A PLANT" can be found in both Chinese and western culture, the difference is that western culture stresses the similarity between the growing process of a plant and the growth of a man; while in Chinese culture life can be projected to a static tree image. The expression "the root of life" in English does not refer an individual's life, but means the origin of life as an abstract concept. Due to the specification of root metaphor's use in Chinese, there is a large overlap between root = origin and root = importance. The meaning of root metaphor in English is limited to the highlight of "origin" rather than "importance". As a Chinese native speaker, Yang can sense that in the original Chinese, root is applied to stress the importance of the jade to Baoyu, so he chose to reserve the metaphor and delivered the literal translation "the root of Baoyu's life". Yet to English readers, the literal translation "the root of Baoyu's life" may not activate the meaning that "the jade is important”, therefore Hawks chose the more direct translation- “the jade is Baoyu's very life”, abandoning the metaphorical form to make it easier for English readers to understand.

Apart from the above translations demonstrating the difference between "root metaphor" comprehension in English and Chinese, the concrete usage of root metaphor in Chinese can also be seen in the projection 
between “root” and "base” or “lower part of something”. In the original Chinese, phrases like “窗户根 the root of window”, “墙根 the root of wall”, “舌根 the root of tongue” appeared many times, yet none of the literal translation can be found in the English translation. For one reason, omitting this trivial metaphor won't cause many damage in the meaning; for another, the abstractness of "root metaphor" in English makes it hard to be applied in any specific item.

\section{Corpus Analysis}

Through the analysis of the above metaphor translating examples, two differences between Chinese and English native speakers can be found: (1) Root as an inseparable part of a plant in Chinese cognition VS the binary perception of root and what's above the ground; (2) The concreteness of root metaphor in Chinese and the abstractness of root metaphor in English. In the following paper, more data will be provided to support these two points with the help of Modern Chinese Corpus and COCA.

12,338 search results were found when we run a search for the character “根” in the online corpus of Contemporary Chinese, 2,000 sentences were selected randomly as the material for further analysis. By running a manual filtering of the 2,000 sentences, only 345 root metaphors are found. Meanwhile, we have searched for the word "root" in the online corpus COCA and the first thousand sentences are chosen for analysis. Also by filtering the proper nouns and the other unqualified items, 372 root metaphor are found.

In the following tables, a statistical study will be carried out for the Chinese and English data from two perspectives: (1) the proportion of each specific metaphor; (2) the semantic orientation of the collocating words of root.

Table 2

The Proportion of Specific Root Metaphors in Chinese and English

\begin{tabular}{|c|c|c|c|c|c|c|}
\hline \multirow{3}{*}{$\begin{array}{l}\text { Root } \\
\text { (根)metaphor } \\
\text { In Chinese }\end{array}$} & Total No. & $\begin{array}{l}\text { (root = cause) } \\
\text { 根源 }\end{array}$ & $\begin{array}{l}\text { (Root = beginning) } \\
\text { 扎根, 生根 }\end{array}$ & $\begin{array}{l}(\text { root }=\text { bottom }) \\
\text { 根部，底部 }\end{array}$ & $\begin{array}{l}\text { Uproot } \\
\text { 根除 }\end{array}$ & $\begin{array}{l}\text { Root=importance } \\
\text { 根基, 根本 }\end{array}$ \\
\hline & 468 & 153 & 17 & 10 & 11 & 277 \\
\hline & & $32.6 \%$ & $3.6 \%$ & $2.1 \%$ & $2.3 \%$ & $59.1 \%$ \\
\hline \multirow{3}{*}{$\begin{array}{l}\text { Root } \\
\text { Metaphor in } \\
\text { English }\end{array}$} & Root metaphor & (root=cause) & $\begin{array}{l}\text { (root=beginning) } \\
\text { Take root }\end{array}$ & root=bottom & root out & $\begin{array}{l}\text { root=support } \\
\text { root for }\end{array}$ \\
\hline & 372 & 199 & 90 & 4 & 27 & 56 \\
\hline & & $53.4 \%$ & $24.1 \%$ & $1.0 \%$ & $7.2 \%$ & $15.0 \%$ \\
\hline
\end{tabular}

By comparing root metaphors in Chinese and English, it can be found that there is a large number of "root = cause" metaphors in both Chinese and English. The usage is based on the universal knowledge that a plant has to take root first. Comparatively, the proportion of "root = cause" metaphor is relatively higher in English (53.4\%), while the metaphor "root = importance" is the one that accounts for larger proportion in Chinese, taking up 59.1\%. The statistics has further demonstrated the preliminary concluson in the previous analysis: the integral cognition in Chinese of tree (that root is the inalienable essential part of a plant), and the binary cognition of trees in English (realizing root as the source, but not treating it as the most important part of the tree). In the later part of this paper, further analysis will be made to reveal the semantic preference by looking through the collocated words of the "root" metaphors in Chinese and English.

Another difference in specific "root" metaphor between English and Chinese is that verbs are more 
frequently applied in English, for example, "take root" and "root for" account for $24.1 \%$ and $15 \%$ respectively; "root out" also takes $7.2 \%$. However, few verbs are found in the Chinese correspondent "root metaphor", the same phrase like "take root” in Chinese only accounts for 3.6\%, with "root out” takes only $1.2 \%$.

The contrast can also reflect the perspective difference in the cognition of root-plant relation in English and Chinese. The relationship between root and plant is perceived much as a dynamic temporal process in English, which is probably the reason for the high-frequency of verbs in English root metaphor; while in Chinese, root is often seen as a part of the tree, the horizontal time axis and the vertical static special axis are equally important in Chinese, the static special analysis of the tree structure has been given more weight. The temporal emphasis in English plant cognition and the spatial emphasis in Chinese also coincide with the abstractness of "root" in English and the concreteness of "root" in Chinese, since space is more concrete than time.

The corpus research and statistical analysis has further proved the preliminary conclusion made by analyzing specific translating examples, deepening the understanding of Chinese and English cognitive frame. In the following Table 3, semantic preference of the collocated words of "root" metaphor are studied to explore the pragmatic function and interpersonal meaning of root metaphor.

Table 3

Semantic Preference of Collocated Words of Root Metaphor in Chinese and English

\begin{tabular}{|c|c|c|c|}
\hline & Positive & Neural & Negative \\
\hline $\begin{array}{l}\text { Chinese Root } \\
\text { Metaphor } \\
\text { (root = cause) } \\
\text { The root of- }\end{array}$ & $\begin{array}{l}\text { Freedom/Equality/Fraternity } \\
\text { /Nutrition/Beauty/Great } \\
\text { Power/the superiority of } \\
\text { socialism/economic } \\
\text { revitalization/social } \\
\text { progress/productivity } \\
\text { development/rational connection } \\
\text { / development }\end{array}$ & $\begin{array}{l}\text { Thought/epistemology/class/relig } \\
\text { ion/character/society/thought/the } \\
\text { ory/viewpoint/ } \\
\text { construction policy/economic } \\
\text { product/ reality/objective world; } \\
\text { socialdevelopment/language } \\
\text { development; }\end{array}$ & $\begin{array}{l}\text { contradiction/Laziness/ } \\
\text { Chaos/Problems/Poverty/Superstition/In } \\
\text { equality/Oppressive/Exploitation/Pain/C } \\
\text { rime/Disaster/Error/Crisis/Struggle/stig } \\
\text { ma/attitude } \\
\text { /issues/struggle/revolution/poverty/decli } \\
\text { ne/inequality/failure/tragedy/dictatorship }\end{array}$ \\
\hline 153 & $30(19.6 \%)$ & $57(37.2 \%)$ & $68(44.4 \%)$ \\
\hline $\begin{array}{l}\text { English Root } \\
\text { metaphor (root } \\
=\text { cause) } \\
\text { The root of- }\end{array}$ & $\begin{array}{l}\text { The root of: All love/polite } \\
\text { behavior/talent/important } \\
\text { things/progress/greatness/ } \\
\text { Civilization; }\end{array}$ & $\begin{array}{l}\text { The root of: Difference/social } \\
\text { behavior/debates/new world } \\
\text { order/interpretation/politics/genr } \\
\text { e of music...; Root cause: } \\
\text { discussions/migration }\end{array}$ & $\begin{array}{l}\text { The root } \\
\text { of :Crisis/sickness/psychiatric/all } \\
\text { evil/outbreak/uncertainties/problem/destr } \\
\text { uction/pain/incident/dilemma/crime; } \\
\text { Rootcause:violence/crime/movements/in } \\
\text { surgency/terrorism/variation/tension/con } \\
\text { flicts/problem/racism/poverty/disease/ad } \\
\text { diction/grievance/resentment... }\end{array}$ \\
\hline 199 & $14(7.0 \%)$ & $32(16.0 \%)$ & $153(76.8 \%)$ \\
\hline $\begin{array}{l}\text { Chinese root } \\
\text { metaphor } \\
\text { (root=source) }\end{array}$ & $\begin{array}{l}\text { Take root and settle down; take } \\
\text { root in the fertile soil; take root } \\
\text { in the deep mountains; take root } \\
\text { in the people; }\end{array}$ & Take root in the earth & $\begin{array}{l}\text { It takes root in the old society and } \\
\text { ancient systems. }\end{array}$ \\
\hline 17 & $14(82.3 \%)$ & $2(11.7 \%)$ & $1(5.8 \%)$ \\
\hline $\begin{array}{l}\text { English root } \\
\text { metaphor } \\
\text { take root } \\
\text { (root=source) } \\
\end{array}$ & $\begin{array}{l}\text { Freedom/peace/new } \\
\text { life/hope/forgiveness... }\end{array}$ & $\begin{array}{l}\text { Multi-culturalism/rule of } \\
\text { law/status/project/gospel/essional } \\
\text { ism/democracy/scientific } \\
\text { tradition }\end{array}$ & $\begin{array}{l}\text { Autocracy/AlQaeda/catastrophist } \\
\text { vision/disease/controversy/violence/prob } \\
\text { lem/war/SARS... }\end{array}$ \\
\hline 90 & $14(15.5 \%)$ & 67 (74.4\%) & $9(10 \%)$ \\
\hline
\end{tabular}


(table 3 continued)

\begin{tabular}{|l|l|l|l|}
\hline & Positive & Neural & Negative \\
\hline \multirow{3}{*}{$\begin{array}{l}\text { Chinese root } \\
\text { metaphor } \\
\text { (root=importance }\end{array}$} & $\begin{array}{l}\text { survival/mass/government; } \\
\text { lifeblood/company/socialism/fun } \\
\text { damentals/people/management/a } \\
\text { bility/improvement/benefit/impro } \\
\text { vement/benefit/startingpoint/outl } \\
\text { et/power/guiding ideology }\end{array}$ & $\begin{array}{l}\text { Change/Task/Principle/ } \\
\text { Viewpoint/Aim/Philosophical/Hi } \\
\text { storical/Materialism/Universe;/T } \\
\text { urning/Qualitative/Change/Ideol } \\
\text { ogical } \\
\text { Construction/Part/Difference/Pri } \\
\text { nciple/Need/Function }\end{array}$ & $\begin{array}{l}\text { Problem/Solution/Focus/War; Fundamentality: } \\
\text { Separation/Argument... }\end{array}$ \\
\hline 277 & $112(40.4 \%)$ & $95(34.2 \%)$ & $70(25.2 \%)$ \\
\hline
\end{tabular}

Through the comparison between the root metaphors in English and Chinese, it can be found that "root = cause" is a common conceptual metaphor in both English and Chinese. In both Chinese and English root metaphors, most of the collocated words for "root = cause" metaphors are negative, among which the proportion of negative words in English is as high as 76.8\%, while the proportion in Chinese is $44.4 \%$, much lower than the proportion in English. The reason for this variance can be traced to the cognitive structure of plants in the two languages. In Chinese, root metaphor is applied to highlight both the importance of the root and root as the origin or cause, which makes the semantic preference of collocated words more diversified based on different emphasis. However, root metaphor in English is usually limited by the binary cognition of the plant, root, as the underground part of the plant, is often treated as the invisible or deep-lying cause, that explains why a large proportion of collocated words of "root" metaphor in English are negative.

As to the metaphor "take root = starting point", it is more frequently used in English than Chinese, which is probably associated with the temporal cognition of plant in English. The relationship between root and the plant is more likely to be viewed in a dynamic temporal axis rather than the static spatial analysis in Chinese. Beside the quantative difference of metaphor application, the semantic preference of "taking root" in Chinese is largely positive, yet the correspondent English metaphor is mostly neutral, with positive and negative usage demonstrating a more or less balanced distribution.

The third largest root metaphor is based on the concept "root = importance", this kind of root metaphor takes up a large share in Chinese, with positive semantic preference accounting for $40.4 \%$, overtaking the negative and neutral collocates; while in English such metaphor rarely exists at all, the importance of root is always mentioned together with "root = cause" metaphor. Metaphors solely contributing to the "root = importance" concept in English are hard to find. Phrases like "this is the root of ..." pay much more attention to the concept "root = cause/origin" than "root = essence/importance".

The analysis of the above three conceptual metaphors based on root has revealed the difference between the cognitive structure of plant and the preferred specific root metaphor in English and Chinese. The main difference can be summarized as follows: in the viewpoint of Chinese native speakers, "root" can be a negative cause, but can also be an essential nutrition provider, the two concepts are equally emphasized; while in English speakers' eyes, the semantic preference of root metaphor is prone to negativity, "root" is mostly some unseen problem needing to be uprooted. The corpus research has provided statistical evidence to support this conclusion. 


\section{Conclusion}

The research focused on the contrastive analysis between "root” metaphors of the two English translations of Dream of the Red Mansion. The study is divided into two main parts, the first part is devoted to the analysis of specific "root" metaphor translation examples, the preliminary conclusion has been made about the integral and concrete cognition of "root" in Chinese, and the independent abstract cognition of "root" in English. Then the deductions have been proven by calculating the frequency of "root" metaphors in English and Chinese respectively, and with further study about the semantic preference of the collocated words around the metaphor. The semantic preference of collocates in Chinese demonstrated a more balanced distribution, which is the result of the integral cognition of plant and root in Chinese. However, "root" metaphors in English are largely negative, which is closely related to the binary cognition of plant in English speaking world. Besides, the statistics also revealed a higher proportion of verbs in English root metaphor, which further proved the dynamic perspective of plant cognition in English, which is contrary to the static analysis of plant in Chinese.

The reason behind these cognitive differences can be traced to the fact that Chinese is a hieroglyphic language; the Chinese characters of all the essential parts of a plant share the same component “木（wood）”, which strengthens the cognitive connection between different parts of the plant. Besides, the variance in folk theory also contributes to the concrete and static cognition of plant and human relationship in Chinese, and the correspondent abstract dynamic cognition in English. In many Chinese myths, everything in the natural world can turn to the form human being if they are determined to go through harsh training for thousands years. The cognitive efforts required to connect a tree to an individual is relatively less. However, in common English myths, a single lifeless tree can only acquire intelligence when magic has been made by a witch or wizard, yet plants can't become humans by themselves. Apart from the analysis in this paper, more explanations of the cognitive differences still need to be found through the perspectives of psychological analysis, natural philosophy and traditional cultural studies.

\section{References}

Cao, X. Q. (2001). A dream of red mansions (four volumes). (X. Y. Yang \& Dai N. D., Trans.). Beijing: Foreign Language Press. Cao, X. Q. (2013). A dream of red mansions (two volumes). Beijing: People’s Literature Publishing House.

De Mendoza Lbanez, F. J. R., \& Perez Hernandez, L. (2011). The contemporary theory of metaphor: Myths, developments and challenges. Metaphor and Symbol, 26(3), 161-185.

Frank, R. M. (2008). The language-organism-species analogy: A complex adaptive system approach to shifting perspectives on “language”. Berlin: Walter de Gruyter.

Grady, J. (1997). Foundations of meanings: Primary metaphors and primary scenes. Berkeley: University of California.

Hawks, D. (1986). The story of stone. Great Britain: Penguin Books Led.

Hawkins, B. (2001). Ideology, metaphor and iconographic reference. Amsterdam: John Benjamins.

Hu, K. B. (2011). An introduction to corpus translation. Shanghai: Shanghai Jiaotong University Press.

Lakoff, G., \& Johnson, M. (1980). Metaphors we live by. Chicago: Chicago University Press.

Lakoff, G., \& Johnson, M. (1999). Philosophy in the flesh: The embodied mind and its challenge to western thought. New York: Basic Books.

Kovecses, Z. (2005). Metaphor in culture: Universality and variation. Cambridge: Cambridge University Press.

Koller, V. (2004). Metaphor and gender in business media discourse: A critical cognitive study. New York: Palgrave Macmillan.

Liang, Ma. C., Li, W., \& Xu, J. J. (2010). Course on corpus application. Beijing: Foreign Language Teaching and Research Press.

Liu, Z. Q. (2010). A corpus-based study of translator style and translation strategies-A case study of reporting verbs and English translation in Dream of Red Mansions. Journal of PLA Foreign Languages Institute, 33(4), 87-92. 
Liu, Z. Q., Liu, C. P., \& Zhu, H. (2011). A preliminary study of translator styles in four English versions of Dream of the Red Mansion: A corpus-based statistics and analysis. Chinese Translation, (1), 60-64.

Ren, S. Z. (2006). Conceptual metaphor and discourse coherence. Foreign Language Teaching and Research, (2), 91-100.

Shu, D. F. (2011). Metaphor and metonymy. Shanghai: Shanghai Foreign Language Education Press.

Wang, C. L. (2017). Metaphor-based psychological text construction. Journal of Foreign Language Studies, (3), 45-58.

Wang, Y. (2012). Cognitive translation studies. Chinese Translation, (4), 17-23.

Wang, Y. (2014). Cognitive translation studies: Theory and method. Foreign Language and Foreign Language Teaching, (2), 1-8.

Xiao, J. Y., \& Li, H. W. (2007). Alienation of poetry metaphors and poetry themes: A cognitive linguistic study of English translation of poetry in A Dream of Red Mansions. Journal of Hong Lou Meng Studies, (1), 231-246.

$\mathrm{Xu}, \mathrm{S}$. H. (2014). The origin, occurrence and construction of metaphor. Foreign Language Teaching and Research, (3), $364-374$.

Xu, S. H., \& He, A. J. (2014). A new theory of metonymic metaphor: Rhetoric research from the perspective of philosophy of mind. Foreign Language Teaching, (1), 1-6.

Zhang, S. S. (2016). Some questions about the latest development of metaphor theory. Foreign Language and Foreign Language Teaching, (1), 90-97.

Zhou, H. Y. (2017). On the coherence pressure of metaphor. Journal of Foreign Languages, (3), 38-44. 